\title{
Thaumarchaeota affiliated with Soil Crenarchaeotic Group are prevalent in the alkaline soil of an alpine grassland in northwestern China
}

\author{
Keqiang Shao ${ }^{1} \cdot$ Xingyu Jiang $^{1} \cdot$ Yang Hu$^{1} \cdot$ Xiangming Tang $^{1} \cdot$ Guang Gao ${ }^{1}$
}

Received: 16 November 2018 / Accepted: 13 June 2019 / Published online: 26 June 2019

(C) Università degli studi di Milano 2019

\begin{abstract}
Purpose Thaumarchaeota are key players within the global nitrogen cycle. Investigations of the Thaumarchaeota communities are important for an integrated understanding of nitrogen nutrient cycle in soil ecosystems. Therefore, the objective of this study was to examine the presence and diversity of Thaumarchaeota within an alkaline soil in the Bayinbuluke alpine grassland, China. Methods The community DNAs were directly extracted from soil samples, collected on 15 July 2014, and paired-end V5-V6 amplicons of the 16S rRNA gene were sequenced by Illumina Miseq. Sequencing reads were processed using the Quantitative Insights Into Microbial Ecology (QIIME) v. 1.8.0 pipeline. After quality control, the validated sequence reads were classified into different operational taxonomic units (OTUs) based on a 97\% identity level, using the Uclust algorithm to generate stable OTUs. The longest sequence in each cluster was chosen to be the representative sequence, and sequences were annotated using the Silva rRNA database project.

Result In the analyzed grassland soil, Thaumarchaeota had a relative abundance of 3.65 to $51.07 \%$ of the microbial community (mean $=20.20 \%$ ), representing the most dominant phylum. The thaumarchaeal community was dominated by the Soil Crenarchaeotic Group (SCG, 34.55 to $99.82 \%$, mean $=95.10 \%$ ), with specifically low fraction of the ammonia-oxidizing genus Candidatus Nitrososphaera (2.83 to $30.37 \%$, mean $=13.10 \%$ ) and remaining unclassified genus.

Conclusion Our results show Thaumarchaeota affiliated with SCG were prevalent in the alkaline soil of this grassland.
\end{abstract}

Keywords Alkaline soil, $\cdot$ Illumina amplicon sequencing, $\cdot$ Thaumarchaeota $\cdot$ Soil Crenarchaeotic Group $\cdot$ Candidatus Nitrososphaera

\section{Findings}

Nitrification, a core process in the global nitrogen cycle, is important for the functioning of many ecosystems (Tago et al. 2015). The Thaumarchaeota is involved in nitrification, and plays a key role in ammonia oxidation (Stahl and de la Torre. 2012). Therefore, investigation of the Thaumarchaeota

Electronic supplementary material The online version of this article (https://doi.org/10.1007/s13213-019-01492-5) contains supplementary material, which is available to authorized users.

\section{Keqiang Shao}

kqshao@niglas.ac.cn

1 Taihu Laboratory for Lake Ecosystem Research, State Key Laboratory of Lake Science and Environment, Nanjing Institute of Geography and Limnology, Chinese Academy of Sciences, Nanjing 210008, China communities is important for an integrated understanding of nitrogen nutrient cycle in soil ecosystems. Furthermore, considerable attention is currently being paid to this, because of their unexpected genetic diversity in many environments. Numerous findings from ecological studies on Thaumarchaeota in acid soils have been well discussed in connection with physiology, in several review articles (He et al. 2012). However, our knowledge of Thaumarchaeota communities in alkaline soil is rather limited.

Nitrification in alkaline soils is different from that in acid and neutral soils, and the widely distributed alkaline soils of northern China are a promising location for research (Sigunga et al. 2002; Shen et al. 2008). The Bayinbuluke alpine grassland $\left(42^{\circ} 10^{\prime}-43^{\circ} 30^{\prime} \mathrm{N}, 82^{\circ} 32^{\prime}-86^{\circ} 15^{\prime} \mathrm{E}\right)$ is a typical alpine grassland in the temperate arid zone of China, and lies in the middle of the southern slope of the Tianshan Mountains in the Xinjiang Uygur autonomous region, in the northwest of the country (He et al. 2014). This grassland has a typical alpine 
climate. The annual average precipitation is $265.7 \mathrm{~mm}, 78.1 \%$ of which falls in the growing season. The annual average temperature is $-4.8^{\circ} \mathrm{C}$, with the lowest monthly value of $27.4{ }^{\circ} \mathrm{C}$ in January and a highest monthly value of $11.2^{\circ} \mathrm{C}$ in July (He et al. 2014).

In this study, we examined the presence and diversity of Thaumarchaeota in the soil from the Bayinbuluke alpine grassland. We worked at 16 sampling sites on 15 July 2014 (Fig. S1). At each site, we collected three replicated soil cores $(0-20 \mathrm{~cm})$ using an 8 -cm-diameter soil auger, and for each core surface soil samples $(0$ $5 \mathrm{~cm}$ ) were taken using a slicing disc. After removing plant residues and gravels, the samples were gently and thoroughly homogenized, and immediately stored at $4{ }^{\circ} \mathrm{C}$ for transportation to the laboratory.

The community DNA was directly extracted from the soil samples, using a PowerSoil DNA isolation kit (MoBio Laboratories, Carlsbad, CA, USA) according to the manufacturer's protocol. To avoid subsample bias, DNA obtained from the three subsamples per soil sample was pooled to prepare each sample's PCR template. The V5-V6 hypervariable regions of $16 \mathrm{~S}$ rRNA gene were amplified using the universal primers (forward primer (789F): 5' TAGATACC CSSGTAGTCC 3' and reverse primer (1068R): 5' CTGACGRCRGCCATGC 3') as described previously ( $\mathrm{Su}$ et al. 2017). The V5-V6 amplicons of 16S rRNA gene were sequenced using the paired-end method by Illumina Miseq at Personal Biotechnology Co., Ltd. (Shanghai, China). Sequencing reads (subsequently referred to as "reads") were processed using the Quantitative Insights Into Microbial Ecology (QIIME) v. 1.8.0 pipeline (He et al. 2015).

After quality control, we obtained a total of 432,820 validated sequences reads from the 16 samples, with an average of 27,051 sequence reads for each sample (the minimum from one sample was 17,886 and the maximum was 41,225$)$. These validated sequences were classified into different operational taxonomic units (OTUs), based on an identity threshold of $97 \%$ using the Uclust algorithm (Edgar et al. 2011) to generate final OTUs (He et al. 2015). The longest sequence in each cluster was chosen to be the representative sequence, and sequences were annotated by the Silva rRNA database project (SILVA VERSION SSU11; http://www.arb-silva.de/). The nucleotide sequences generated by pyrosequencing were deposited in the NCBI Sequence Read Archive (SRA) database, with accession number SRP068890.

All soils were slightly alkaline, with $\mathrm{pH}$ values ranging from 7.99 to 8.15 , and the content of total organic carbon (TOC) ranging from 14.62 to $29.50 \%$ (average 20.50\%) (Table 1). Thaumarchaeota was the most abundant microbial phylum in all samples, and had a relative abundance of 3.65 to $51.07 \%$ of all microbial sequences among the 16 samples (average 20.20\%) (Fig. 1a).
Table 1 Geographic coordinates, $\mathrm{pH}$, and total organic carbon (TOC) for soil samples from 16 sampling sites in the Bayinbuluke alpine grassland, China. Samples were taken on 15 July 2014. Sites are indicated by labels B1-B16

\begin{tabular}{|c|c|c|c|}
\hline Sites & Location & $\mathrm{pH}$ & TOC (\%) \\
\hline \multirow[t]{2}{*}{$\mathrm{B} 1$} & $\mathrm{~N} 42^{\circ} 51^{\prime} 51.01^{\prime \prime}$ & \multirow[t]{2}{*}{8.00} & \multirow[t]{2}{*}{20.19} \\
\hline & $\mathrm{E} 84^{\circ} 15^{\prime} 06.73^{\prime \prime}$ & & \\
\hline \multirow[t]{2}{*}{$\mathrm{B} 2$} & $\mathrm{~N} 42^{\circ} 49^{\prime} 30.84^{\prime \prime}$ & \multirow[t]{2}{*}{8.03} & \multirow[t]{2}{*}{14.62} \\
\hline & E $84^{\circ} 23^{\prime} 24.22^{\prime \prime}$ & & \\
\hline \multirow[t]{2}{*}{ B3 } & $\mathrm{N} 42^{\circ} 49^{\prime} 15.69^{\prime \prime}$ & \multirow[t]{2}{*}{8.01} & \multirow[t]{2}{*}{16.03} \\
\hline & E $84^{\circ} 23^{\prime} 53.50^{\prime \prime}$ & & \\
\hline \multirow[t]{2}{*}{ B4 } & $\mathrm{N} 42^{\circ} 40^{\prime} 50.86^{\prime \prime}$ & \multirow[t]{2}{*}{8.15} & \multirow[t]{2}{*}{16.98} \\
\hline & $\mathrm{E} 84^{\circ} 31^{\prime} 50.60^{\prime \prime}$ & & \\
\hline \multirow[t]{2}{*}{ B5 } & $\mathrm{N} 42^{\circ} 41^{\prime} 04.51^{\prime \prime}$ & \multirow[t]{2}{*}{8.03} & \multirow[t]{2}{*}{23.16} \\
\hline & E $84^{\circ} 30^{\prime} 37.74^{\prime \prime}$ & & \\
\hline \multirow[t]{2}{*}{ B6 } & $\mathrm{N} 42^{\circ} 55^{\prime} 28.14^{\prime \prime}$ & \multirow[t]{2}{*}{8.07} & \multirow[t]{2}{*}{23.01} \\
\hline & E $83^{\circ} 47^{\prime} 31.01^{\prime \prime}$ & & \\
\hline \multirow[t]{2}{*}{ B7 } & 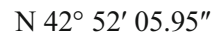 & \multirow[t]{2}{*}{8.05} & \multirow{2}{*}{20.31} \\
\hline & E $83^{\circ} 43^{\prime} 21.12^{\prime \prime}$ & & \\
\hline \multirow[t]{2}{*}{ B8 } & 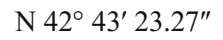 & \multirow[t]{2}{*}{8.05} & \multirow[t]{2}{*}{29.50} \\
\hline & E $83^{\circ} 42^{\prime} 25.04^{\prime \prime}$ & & \\
\hline \multirow[t]{2}{*}{ B9 } & 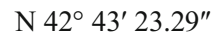 & \multirow[t]{2}{*}{8.06} & \multirow[t]{2}{*}{25.29} \\
\hline & E $83^{\circ} 43^{\prime} 24.02^{\prime \prime}$ & & \\
\hline \multirow[t]{2}{*}{$\mathrm{B} 10$} & $\mathrm{~N} 42^{\circ} 49^{\prime} 41.80^{\prime \prime}$ & \multirow[t]{2}{*}{8.08} & \multirow[t]{2}{*}{22.15} \\
\hline & $\mathrm{E} 84^{\circ} 24^{\prime} 25.30^{\prime \prime}$ & & \\
\hline \multirow[t]{2}{*}{ B11 } & $\mathrm{N} 43^{\circ} 04^{\prime} 29.87^{\prime \prime}$ & 8.02 & 16.48 \\
\hline & E $84^{\circ} 46^{\prime} 49.09^{\prime \prime}$ & & \\
\hline $\mathrm{B} 12$ & $\mathrm{~N} 43^{\circ} 04^{\prime} 57.69^{\prime \prime}$ & 7.99 & 21.61 \\
\hline & E $85^{\circ} 48^{\prime} 48.48^{\prime \prime}$ & & \\
\hline $\mathrm{B} 13$ & $\mathrm{~N} 43^{\circ} 06^{\prime} 35.11^{\prime \prime}$ & 8.02 & 21.88 \\
\hline & $\mathrm{E} 85^{\circ} 27^{\prime} 33.77^{\prime \prime}$ & & \\
\hline B14 & $\mathrm{N} 43^{\circ} 05^{\prime} 09.51^{\prime \prime}$ & 8.00 & 18.31 \\
\hline & E $85^{\circ} 49^{\prime} 29.60^{\prime \prime}$ & & \\
\hline B15 & $\mathrm{N} 43^{\circ} 03^{\prime} 10.28^{\prime \prime}$ & 8.09 & 17.74 \\
\hline & E $85^{\circ} 58^{\prime} 53.20^{\prime \prime}$ & & \\
\hline B16 & $\mathrm{N} 43^{\circ} 03^{\prime} 54.52^{\prime \prime}$ & 8.05 & 20.73 \\
\hline & E $85^{\circ} 59^{\prime} 13.04^{\prime \prime}$ & & \\
\hline
\end{tabular}

Our unexpected findings of the high abundance of Thaumarchaeota in the alkaline soils of this alpine grassland contrast with those of Ochsenreiter et al. (2003) and Lehtovirta et al. (2009), who reported that the Thaumarchaeota constitute only 5\% of the total prokaryotic community in many soils. Two reasons may account for the phenomenon that the Thaumarchaeota occurred at high abundance in the Bayinbuluke alkaline grassland soil. (1) The carbon content of the soil in our study was markedly higher than that in other studies (Ochsenreiter et al. 2003; Lehtovirta et al. 2009). We found that the average TOC content of the soil was $20.50 \%$ (range 14.62 to $29.50 \%$ ) (Table 1), while the study of Ochsenreiter et al. (2003) reported a TOC of only $2.6 \%$ and the TOC content is lower in another study (Lehtovirta et al. 2009). Levicnik-Höfferle et al. (2012) also reported that the Thaumarchaea appeared to assimilate organic matter, followed by mineralization and ammonia oxidation. (2) The use of high-throughput sequencing in our study, could explore the panorama of 

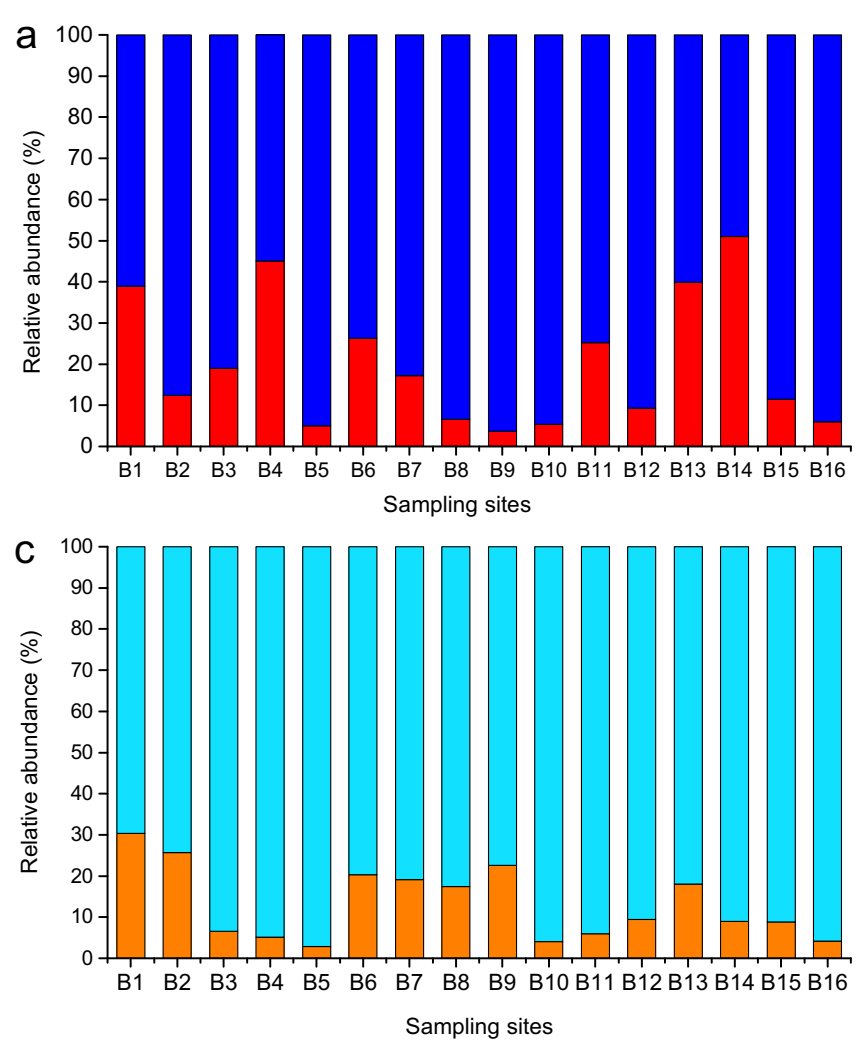

Fig. 1 a Relative abundances of Thaumarchaeota at the phylum level in the soils of the Bayinbuluke alpine grassland. b Thaumarchaeota community composition based on relative abundances in the soils of the

the diversity of soil microbes (Bik et al. 2012; Zinger et al. 2012). Our methodology contrasted with the $16 \mathrm{~S}$ RNA surveys and real time PCR used by Ochsenreiter et al. (2003) and Lehtovirta et al. (2009); in each of these two previous studies rather small amounts of Thaumarchaeota were detected. Our observation could be random, because our results were obtained with soil sampled on a single occasion. Furthermore, only few alkaline soils have been studied to date. Therefore, further studies of other alkaline soils would be needed to confirm these findings.

The relative abundance analysis showed that the Thaumarchaeota from this alkaline alpine grassland included seven subgroups: (i) Soil Crenarchaeotic Group (SCG), (ii) Miscellaneous Crenarchaeotic Group, (iii) Marine Group I, (iv) HDBA-SITS413, (v) Marine Benthic Group B, (vi) Group C3, and (vii) Sc-EA05 (Fig. 1b). The SCG represented the major part of the thaumarchaeal group for each sample, and was the most ubiquitous sub-group: the mean relative abundance was $95.10 \%$, with a range from 34.55 to $99.82 \%$ for the 16 samples. The other six subgroups accounted for only a low fraction of the thaumarchaeal group (4.90\%).

The BLAST searches conducted with our SCG sequences revealed that Candidatus Nitrososphaera represented only a small part of each sample, with relative abundance ranging from

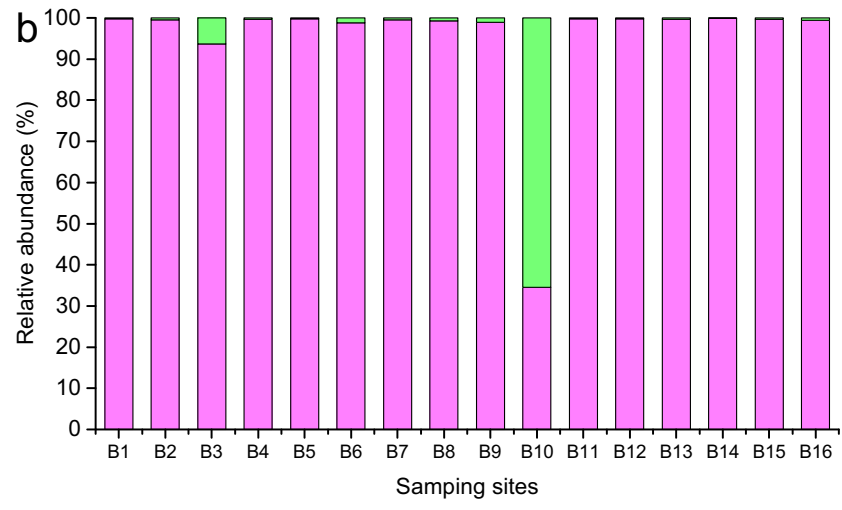

Other taxonomic groups $\square$ Rare taxa (Miscellaneous Crenarchaeotic Group,
Marine Group I, HDBA-SITS413, Marine Benthic
Group B, Group C3,Sc-EA05)
$\square$ Soil Crenarchaeotic Group(SCG)

Thaumarchaeota

unclassified genus

Candidatus Nitrososphaera

Bayinbuluke alpine grassland. c Relative abundances of Soil Crenarchaeotic Group at the genus level in the soils of the Bayinbuluke alpine grassland

2.83 to $30.37 \%$, with a mean of $13.10 \%$, of the thaumarchaeal group; Candidatus Nitrososphaera was designated a major genus. The other SCG sequences corresponded to unclassified genus (Fig. 1c). Candidatus Nitrososphaera is an important taxa involved in the soil nitrogen cycle (Spang et al. 2012), with species being involved in nitrification by performing oxidation of ammonia (Schneider et al. 2015). In the Bayinbuluke grassland soil, most thaumarchaeal $16 \mathrm{Sr}$ RNA Illumina sequence reads belonged to the ammoniaoxidizing genus Candidatus Nitrososphaera and other unclassified members of the SCG. Our result is in good agreement with the results from savanna soils in Kruger National Park, South Africa (Rughöft et al. 2016).

In conclusion, the present study revealed that in the alkaline soil of the Bayinbuluke alpine grassland soil in China, the Thaumarchaeota represented an average of $20.20 \%$ of the total soil microbial community, and was a prevalent phylum. The Thaumarchaeota was dominated by the SCG, with a low fraction of sequences related to the ammonia-oxidizing genus Candidatus Nitrososphaera.

Acknowledgments We thank staff at the Institute of Lake Bosten, of the Environmental Protection Bureau of Bayingolin Mongolia Autonomous Prefecture, for help with sample collection. We are grateful to the editor and anonymous reviewers for their constructive comments and helpful suggestions. 
Funding This study was funded by the "One-Three-Five" Strategic Planning of Nanjing Institute of Geography and Limnology, Chinese Academy of Sciences (Grant No. NIGLAS2017GH05), the National Natural Science Foundation of China (Grant No. 41790423) and the Special Environmental Research Funds for Public Welfare of the State Environmental Protection Administration (Grant No. 201309041).

\section{Compliance with ethical standards}

Conflict of interest The authors declare that they have no conflict of interest.

Research involving human participants and/or animals This article does not contain any studies with human participants or animals.

Informed consent A statement regarding informed consent is not applicable for this study.

\section{References}

Bik HM, Porazinska DL, Creer S et al (2012) Sequencing our way towards understanding global eukaryotic biodiversity. Trends Ecol Evo 27(4):233-243

Edgar RC, Haas BJ, Clemente JC, Quince C, Knight R (2011) Uchime improves sensitivity and speed of chimera detection. Bioinformatics 27(16):2194-2200

He GX, Li KH, Liu XJ, Gong YM, Hu YK (2014) Fluxes of methane, carbon dioxide and nitrous oxide in an alpine wetland and an alpine grassland of the Tianshan Mountains, China. J Arid Land 6(6):717724

He JZ, Hu HW, Zhang LM (2012) Current insights into the autotrophic thaumarchaeal ammonia oxidation in acidic soils. Soil Biol Biochem 55(6):146-154

He Y, Caporaso JG, Jiang XT, Sheng HF, Huse SM, Rideout JR, Edgar RC, Kopylova E, Walters WA, Knight R, Zhou HW (2015) Stability of operational taxonomic units: an important but neglected property for analyzing microbial diversity. Microbiome 3(1):20

Lehtovirta LE, Prosser JI, Nicol GW (2009) Soil pH regulates the abundance and diversity of Group1.1c Crenarchaeota. FEMS Microbiol Ecol 70(3):367-376

Levicnik-Höfferle S, Nicol GW, Ausec L, Mulec I, Prosser JI (2012) Stimulation of thaumarchaeal ammonia oxidation by ammonia derived from organic nitrogen but not inorganic nitrogen. FEMS Microbiol Ecol 80(1):114-123
Ochsenreiter T, Selezi D, Quaiser A, Bonchosmolovskaya L, Schleper C (2003) Diversity and abundance of Crenarchaeota in terrestrial habitats studied by $16 \mathrm{~S}$ RNA surveys and real time PCR. Environ Microbiol 5(9):787-797

Rughöft S, Herrmann M, Lazar CS, Cesarz S, Levick SR, Trumbore SE, Küsel K (2016) Community composition and abundance of bacterial, archaeal, and nitrifying populations in savanna soils on contrasting bedrock material in Kruger National Park, South Africa. Front Microbiol 7:1638

Schneider D, Engelhaupt M, Allen K, Kurniawan S, Krashevska V, Heinemann M, Nacke H, Wijayanti M, Meryandini A, Corre MD, Scheu S, Daniel R (2015) Impact of lowland rainforest transformation on diversity and composition of soil prokaryotic communities in Sumatra (Indonesia). Front Microbiol 6:1339

Shen JP, Zhang LM, Zhu YG, Zhang JB, He JZ (2008) Abundance and composition of ammonia-oxidizing bacteria and ammonia-oxidizing archaea communities of an alkaline sandy loam. Environ Microbiol 10(6):1601-1611

Sigunga DO, Janssen BH, Oenema O (2002) Ammonia volatilization from vertisols. Eur J Soil Sci 53(2):195-202

Spang A, Poehlein A, Offre P, Zumbrägel S, Haider S, Rychlik N, Nowka B, Schmeisser C, Lebedeva EV, Rattei T, Böhm C, Schmid M, Galushko A, Hatzenpichler R, Weinmaier T, Daniel R, Schleper C, Spieck E, Streit W, Wagner M (2012) The genome of the ammoniaoxidizing Candidatus Nitrososphaera gargensis: insights into metabolic versatility and environmental adaptations. Environ Microbiol 14(12):3122-3145

Stahl DA, dela Torre JR (2012) Physiology and diversity of ammoniaoxidizing archaea. Annu Rev Microbiol 66(66):83-101

Su P, Lou J, Brookes PC, Luo Y, He Y, Xu JM (2017) Taxon-specific responses of soil microbial communities to different soil priming effects induced by addition of plant residues and their biochars. J Soils Sediments 17(3):674-684

Tago K, Okubo T, Shimomura Y, Kikuchi Y, Hori T, Nagayama A, Hayatsu M (2015) Environmental factors shaping the community structure of ammonia-oxidizing bacteria and archaea in sugarcane field soil. Microbes Environ 30(1):21-28

Zinger L, Gobet A, Pommier T (2012) Two decades of describing the unseen majority of aquatic microbial diversity. Mol Ecol 21(8): 1878-1896

Publisher's note Springer Nature remains neutral with regard to jurisdictional claims in published maps and institutional affiliations. 